\title{
Deep brain stimulation for the treatment of disorders of consciousness and cognition in traumatic brain injury patients: a review
}

\author{
Bornali Kundu, MD, PhD, ${ }^{1}$ Andrea A. Brock, MD, MSCl, ${ }^{1}$ Dario J. Englot, MD, PhD, ${ }^{2}$ \\ Christopher R. Butson, PhD, ${ }^{3}$ and John D. Rolston, MD, PhD ${ }^{1}$
}

\begin{abstract}
Departments of ${ }^{1}$ Neurosurgery and ${ }^{3}$ Biomedical Engineering, University of Utah, Salt Lake City, Utah; and ${ }^{2}$ Department of Neurosurgery, Vanderbilt University Medical Center, Nashville, Tennessee
\end{abstract}

\begin{abstract}
Traumatic brain injury (TBI) is a looming epidemic, growing most rapidly in the elderly population. Some of the most devastating sequelae of TBI are related to depressed levels of consciousness (e.g., coma, minimally conscious state) or deficits in executive function. To date, pharmacological and rehabilitative therapies to treat these sequelae are limited. Deep brain stimulation (DBS) has been used to treat a number of pathologies, including Parkinson disease, essential tremor, and epilepsy. Animal and clinical research shows that targets addressing depressed levels of consciousness include components of the ascending reticular activating system and areas of the thalamus. Targets for improving executive function are more varied and include areas that modulate attention and memory, such as the frontal and prefrontal cortex, fornix, nucleus accumbens, internal capsule, thalamus, and some brainstem nuclei. The authors review the literature addressing the use of DBS to treat higher-order cognitive dysfunction and disorders of consciousness in TBI patients, while also offering suggestions on directions for future research.
\end{abstract}

https://thejns.org/doi/abs/10.3171/2018.5.FOCUS18168

KEYWORDS deep brain stimulation; consciousness; coma; vegetative state; minimally conscious state; cognition; thalamus

$\mathrm{T}$ RAUMATIC brain injury (TBI) is a medical and surgical epidemic affecting at least 1.7 million individuals yearly in the United States and causing 1.5 million hospitalizations in the European Union yearly. ${ }^{18,21}$ Its incidence is growing, from an estimated incidence of 521 per 100,000 in 2001 in the US ${ }^{21}$ (and 235 per 100,000 in Europe $^{70}$ ) to 824 per 100,000 people in the US in $2010 .{ }^{21}$ The most common causes for TBI are falls (35\%) and motor vehicle accidents (17\%), and males sustain 1.4 times more brain injuries than females..$^{18}$ Although TBI affects individuals of all ages, there has been a relative increase in incidence in older populations, abetted by the increased use of anticoagulation therapy.

Some of the most devastating sequelae of TBI are related to depressed levels of consciousness or deficits in higher-order cognitive functions. ${ }^{21}$ Levels of consciousness are separated clinically into different states: the minimally conscious state (MCS), the vegetative state (VS), and coma. ${ }^{26}$ Approximately $14 \%$ of patients admitted for trauma are discharged in a VS, and $52 \%$ will regain consciousness within 1 year. ${ }^{44}$ Patients typically transition out of coma within weeks to a VS or MCS. ${ }^{22}$

Conservative treatment has had limited success in treating disorders of consciousness. Central nervous system (CNS) stimulators (e.g., levodopa, amantadine) and depressants (zolpidem) have had minimal and inconsistent effects. ${ }^{24,45,71}$ Electrical stimulation of the brain is a potential alternative treatment for the sequelae of TBI. Although noninvasive methods such as transcranial magnetic stimulation (TMS) and transcranial direct-current stimulation have been widely studied ${ }^{45}$ there are far fewer reports of deep brain stimulation (DBS) of subcortical targets.

DBS targets deep brain nuclei and white matter tracts with millimetric accuracy. The cognitive and consciousness sequelae of TBI are related to direct loss of cortical neurons, disconnection of distant cortical areas, and local

ABBREVIATIONS CNS = central nervous system; DBS = deep brain stimulation; $D R=$ dorsal raphe; EEG = electroencephalography; MCS = minimally conscious state; $\mathrm{MR}=$ median raphe; $\mathrm{MSN}=$ medial septal nucleus; $\mathrm{TBI}$ = traumatic brain injury; TMS = transcranial magnetic stimulation; VS = vegetative state.

SUBMITTED April 1, 2018. ACCEPTED May 11, 2018.

INCLUDE WHEN CITING DOI: 10.3171/2018.5.FOCUS18168. 
neuronal circuit dysregulation in the form of dysregulated neurotransmitter levels and cellular damage. ${ }^{25}$ Neuropathological autopsy reports ${ }^{1,27}$ and whole brain imaging ${ }^{28}$ have shown that direct thalamic damage from injury or postinjury degeneration may also be a primary mechanism causing disorders of conciousness. ${ }^{28,63}$ Importantly, certain thalamic nuclei are required for arousal and attention. ${ }^{63}$ Thus, thalamic nuclei and connected white matter tracts and nuclei have become important targets for DBS to treat disorders of consciousness.

DBS has proven efficacy for cognitive and movement disorders ${ }^{20,52}$ and potential for the treatment of other disorders, such as depression. ${ }^{17}$ TBI patients often develop these same clinical diseases (e.g., tremor, depression) because of direct structural brain damage or secondary damage from the injury. ${ }^{4,16}$ DBS has shown efficacy in treating subpopulations of TBI patients with such comorbidities, ${ }^{37,65}$ yet the effect of DBS on higher-order functions is unclear. We review the literature addressing the use of DBS to treat higher-order cognitive dysfunction and disorders of consciousness in TBI patients (see Table 1).

\section{DBS for Arousal in TBI}

\section{Reticulothalamic System Stimulation and Modulation of Arousal in Animal Models}

In normal physiology, the midbrain reticular formation within the brainstem drives thalamic nuclei through cholinergic as well as glutaminergic connections. ${ }^{67}$ From thalamic relay nuclei, thalamocortical fibers synapse on layer IV cells in the cortex, driving arousal.53,67 Moruzzi and Magoun ${ }^{53}$ showed that "high-frequency" $(300-\mathrm{Hz})$ stimulation of cat reticular formation results in electroencephalography (EEG) "desynchronization.” Desynchronization is a hallmark of cortical activation and arousal in animals and humans.

The first cellular-level evidence of intralaminar thalamic nuclei transfer input from the brainstem reticular formation to the cortex and striatum was demonstrated in cats by using electrode recordings and horseradish peroxidase fiber tracking. ${ }^{68}$ In these experiments, the rostral pontine tegmentum was lesioned and degeneration of the fibers en passage was allowed in order to prevent artifactual recordings. High-frequency $(100-\mathrm{Hz})$ stimulation of the central thalamus in intact rodents ${ }^{66}$ resulted in increased arousal and improved behavioral performance on tasks using attention and memory. Low-frequency $(10-\mathrm{Hz})$ stimulation decreased arousal and led to sleep spindle formation and even absence seizures. ${ }^{46}$ Some of these early animal studies led to the first case studies using DBS to treat brain injury patients.

\section{DBS to Treat Disorders of Consciousness in TBI Patients}

One of the first clinical descriptions of DBS for treatment of disorders of consciousness was a case report published in $1969 .{ }^{31}$ The authors described a 26-year-old man in a persistent VS after TBI. Stimulation of electrodes implanted in the left ventral anterior nucleus of the thalamus (at $50 \mathrm{~Hz}$ ) and the right pallidum (at $8 \mathrm{~Hz}$ ) produced increased spontaneous limb and eye movements and increased duration of arousal. Post-stimulation, the EEG showed decreased slow waves in the left temporal cortex and increased fast spiking in the bilateral cortex as well as thalamus and pallidum.

In 1990, Tsubokawa et al. ${ }^{72}$ published an early case series addressing stimulation and arousal in coma patients implanted with electrodes in the mesencephalic reticular formation or nonspecific thalamus. By 6 months, 4 of 8 patients had emerged from the VS state to follow commands and exhibited EEG desynchronization and increased regional cerebral blood flow. In that study, stimulation was delivered every 2 hours for 30 minutes at a time (off at night) at $50 \mathrm{~Hz}$. In a follow-up study, ${ }^{74} 21$ patients (2 with TBI, 19 with vascular injuries, including stroke) had electrodes implanted 3 months after injury. After 19 months, 8 patients (38\%) could follow commands. Stimulation was delivered every 2-3 hours for 30 minutes at a time (off at night) at $25 \mathrm{~Hz}$ in the centromedian nucleus of the thalamus or midbrain reticular formation. After 10 years, no additional patients emerged from coma. Note that these studies have been criticized for not giving patients adequate time to recover consciousness on their own prior to implantation. ${ }^{73}$

With the aim of activating the cortex and producing some degree of functional recovery, Cohadon and Rich$\mathrm{er}^{12}$ stimulated the central nucleus of the thalamus in 25 patients 3 months after injury. Bipolar stimulation at 50 $\mathrm{Hz}$ was delivered 12 hours per day for 2 months. Twelve patients showed clinical improvement, but all remained moderately to severely disabled. This cohort study illustrates a central challenge in linking DBS to recovery of consciousness because, as the authors note, up to $35 \%$ of VS patients and $81 \%$ of MCS patients will recover spontaneously within 6 months to 1 year. ${ }^{23,41,63}$

Cognitive testing during stimulation-on and stimulation-off periods is necessary to discern the arousal effects of DBS versus a "lesion effect" from implantation. Schiff et al. ${ }^{62}$ placed bilateral thalamic intralaminar and paralaminar leads in a 38-year-old man who had experienced a TBI 6 years earlier. The patient showed improved arousal behavior and improved limb movement and oral feeding responses during periods when $100-\mathrm{Hz}$ DBS was on. Although this was a case study, because the experiment used a blinded, crossover design with multiple DBS on and off periods (each period was 1 month long), it shows that DBS can drive behavioral improvement. Stimulation frequency and amplitude were titrated to obtain the best response for this patient.

The multi-institutional Cortical Activation by Thalamic Stimulation (CATS) study, which enrolled 3 of 40 screened TBI patients (all injured 2-8 years earlier), implemented bilateral stimulation of anterior intralaminar thalamic nuclei and adjacent areas from 18 to 48 months. ${ }^{48}$ Patients went through an initial testing phase during which optimal stimulation settings were determined based on behavior. The patients were stimulated on average at $100 \mathrm{~Hz}$ (range $80-110 \mathrm{~Hz}$ ) during the daytime. The Coma Recovery Scale-Revised (CRS-R) scores improved from 6 and 8 for the 2 VS patients to 9 and 11 at 18 months, respectively, and from 14 to 15 in the MCS patient; however, none of the patients recovered to full consciousness.

Most recently, Chudy et al. ${ }^{11}$ used unilateral $50-\mathrm{Hz}$ 
TABLE 1. Studies evaluating DBS to treat arousal and executive function in TBI patients or TBI animal models

\begin{tabular}{|c|c|c|c|c|}
\hline Authors \& Year & Population & Stimulation Location & $\begin{array}{l}\text { Frequency of } \\
\text { Stimulation }\end{array}$ & Results \\
\hline \multicolumn{5}{|l|}{ Arousal } \\
\hline Hassler et al., 1969 & $1 \mathrm{VS} \mathrm{pt}$ & $\begin{array}{l}\text { Lt ventral ant thalamus \& rt } \\
\text { pallidum }\end{array}$ & $\begin{array}{l}\text { Ventral ant thala- } \\
\text { mus at } 50 \mathrm{~Hz} \& \\
\text { pallidum at } 8 \mathrm{~Hz}\end{array}$ & Increased arousal \\
\hline $\begin{array}{l}\text { Tsubokawa et al., } \\
1990\end{array}$ & $8 \mathrm{VS}$ pts & $\begin{array}{l}\text { Median reticular formation ( } \mathrm{n} \\
\quad=2 \text { ), central thalamic nuclei } \\
\text { (unilat, } n=6 \text { ) }\end{array}$ & $50 \mathrm{~Hz}$ & $\begin{array}{l}4 \text { pts emerged; EEG desynchronization, increased } \\
\text { CBF \& regional metabolism }\end{array}$ \\
\hline $\begin{array}{l}\text { Cohadon \& Richer, } \\
1993\end{array}$ & 25 VS pts & Central nucleus of the thalamus & $50 \mathrm{~Hz}$ & 13 showed clinical improvement \\
\hline $\begin{array}{l}\text { Yamamoto et al., } \\
2010\end{array}$ & $21 \mathrm{VS} p \mathrm{~s}$ & $\begin{array}{l}\text { Centromedian nucleus of the } \\
\text { thalamus }(n=19) \& \text { midbrain } \\
\text { reticular formation }(n=2)\end{array}$ & $25 \mathrm{~Hz}$ & $\begin{array}{l}8 \text { had emerged at } 16 \text {-mo mark, no others emerged } \\
\text { over } 10 \text { yrs }\end{array}$ \\
\hline Schiff et al., 2007 & $1 \mathrm{MCS} p t$ & Central thalamic nuclei (bilat) & $100 \mathrm{~Hz}$ & $\begin{array}{l}\text { The pt showed increased signs of arousal, better feed- } \\
\text { ing \& motor behaviors }\end{array}$ \\
\hline Magrassi et al., 2016 & $\begin{array}{l}2 \text { VS pts \& } 1 \\
\text { MCS pt }\end{array}$ & $\begin{array}{l}\text { Ant intralaminar nuclei \& para- } \\
\quad \text { laminar areas (bilat) }\end{array}$ & $80-110 \mathrm{~Hz}$ & Increased arousal \\
\hline Chudy et al., 2017 & $\begin{array}{l}14 \text { pts (MCS } \\
\quad \& \text { VS) }\end{array}$ & Central thalamic nuclei (unilat) & $25 \mathrm{~Hz}$ & $\begin{array}{l}4 \text { pts emerged ( } 3 \text { MCS pts \& } 1 \text { VS pt); increased level } \\
\text { of consciousness, some returned to independent } \\
\text { life w/ disability }\end{array}$ \\
\hline \multicolumn{5}{|l|}{ Executive function } \\
\hline $\begin{array}{l}\text { Carballosa Gonzalez } \\
\text { et al., } 2013\end{array}$ & 79 rats & Median \& dorsal raphe nuclei & & $\begin{array}{l}\text { Improved spatial working memory, reduced cortical } \\
\text { vol loss }\end{array}$ \\
\hline Lee et al., 2013 & 56 rats & Medial septal nucleus & & Improved spatial working memory \\
\hline Lee et al., 2015 & 136 rats & Medial septal nucleus cont stim & & Improved object exploration \& spatial working memory \\
\hline Rezai et al., 2016 & 4 pts & $\begin{array}{l}\text { Nucleus accumbens \& ant limb } \\
\text { of int capsule (bilat) }\end{array}$ & $80-210 \mathrm{~Hz}$ & $\begin{array}{l}\text { Improved functional (encompassing self-awareness, } \\
\text { ability to perform ADL, \& communication) \& cogni- } \\
\text { tive (encompassing executive function, working } \\
\text { memory, \& attention) composite scores }\end{array}$ \\
\hline
\end{tabular}

$\mathrm{ADL}=$ activities of daily living; ant = anterior; $\mathrm{CBF}=$ cerebral blood flow; cont stim = continuous stimulation; int = internal; $\mathrm{NR}=$ not reported; $\mathrm{pt}=$ patient .

stimulation of the centromedian parafascicular complex to treat a group of $14 \mathrm{MCS}$ and VS patients who had either traumatic or ischemic encephalopathy but had intact evoked potentials, positron emission tomography (PET)detectable brain metabolism, and structural integrity of the brainstem grossly assessed using MRI. Three MCS patients and $1 \mathrm{VS}$ patient emerged to consciousness-a $29 \%$ response rate. Treatment was started an average of 140 days after injury in those patients. Again, the authors agree that it is not possible to rule out that these patients were going to emerge spontaneously to consciousness without DBS, but they point out that the rates at which the patients recovered through rehabilitation were faster than previously reported rates of recovery in patients who were not treated with DBS.

\section{How to Determine Whether DBS Will Work in Coma}

Based on the experimental and clinical data described above, DBS to treat disorders of consciousness appears to require intact circuitry among the midbrain reticular formation, thalamus, and cortex to allow modulation of the global brain function. One challenge has been how to determine whether a coma patient has sufficient structural integrity within the thalamocortical loops to sustain brain function beyond simple arousal-and thereby allow DBS to be effective (Fig. 1A). ${ }^{63}$ In addition to the clinical examination discerning VS from MCS, most studies designed to test the effects of DBS on consciousness have radiographic criteria for inclusion - namely no radiographic evidence of damage to the thalamus, certain areas of the cortex, or the brainstem.

Some electrophysiological measures have been used to assess global brain function for both diagnosis and prognosis of recovery in patients with disorders of consciousness (Fig. 1B)..$^{59}$ Some of these evoked responses are the Vth wave of the auditory brainstem response, the N20 somatosensory evoked potential, desynchronization patterns of EEG, a pain-related P250 event-related potential $>7 \mu \mathrm{V}$, and more complex evoked potentials such as the P300 reflecting higher-order cognitive processing. ${ }^{59}$ Yamamoto et al. ${ }^{74}$ used these tests to predict which patients would recover after DBS. Of the 107 patients studied, 21 patients were implanted with DBS, 10 of whom met the above-mentioned electrophysiological criteria. Eight of those 10 patients $(80 \%)$ eventually recovered. Of the remaining 86 patients who did not have electrodes implanted, 6 met electrophysiological criteria but none recovered consciousness. The significant difference in the rate of re- 


\section{A Theoretical arousal network}

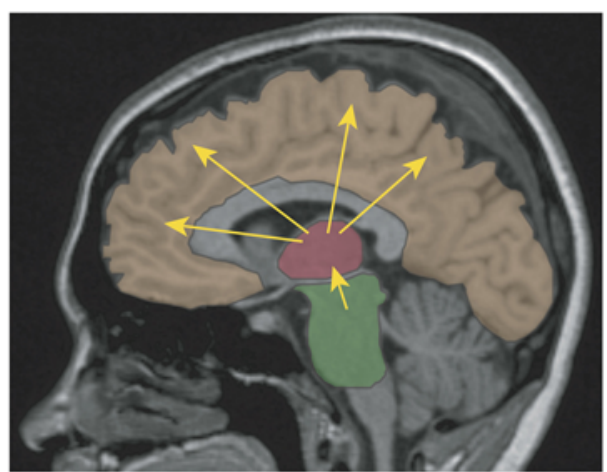

B



-Perceptual evoked responses (e.g. VEP, BAER)

-TMS evoked response (EEG and/or fMRI)

-Perturbational complexity index (PCI)

C

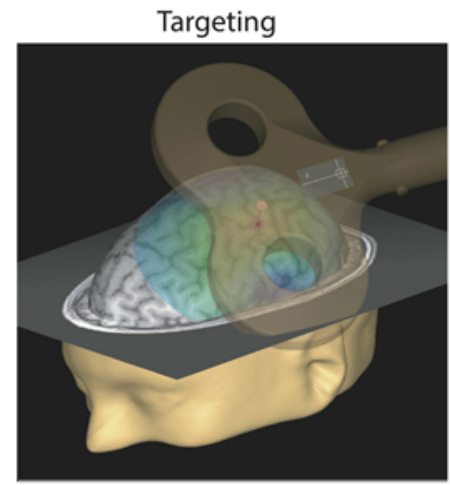

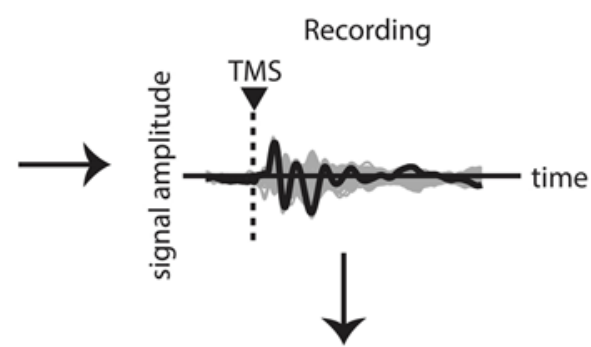

Source space modeling

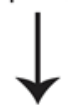

Derive $\mathrm{PCI}$ measure

FIG. 1. How to determine whether DBS will work in a patient in a coma. A: The theoretical arousal network targeted with DBS includes the cortex (orange overlay), thalamus (red overlay), and midbrain and pontine reticular formations (green overlay). The arousal generator originates from signals from the midbrain but may be modulated with stimulation of the thalamic relay centers. Thalamic relay centers project diffusely to cortex. B: The combination of structural measures (including MRI-based assessment of gray matter integrity, diffusion tensor imaging [DTI]-based assessment of white matter integrity), endogenously generated signals of global network integrity (such as in resting-state functional MRI [fMRI]), and newer stimulation-based connectivity measures (including TMS-based evoked response propagation as quantified by the perturbational complexity index [PCI]) may better predict which patients will benefit from DBS to bring about or facilitate arousal. C: The PCI is derived from recording the TMS-evoked response from scalp EEG (black trace is average TMS-evoked response across channels; gray traces are individual channel traces) and then projecting this signal to source space and deriving a measure of complexity based on the manner in which the evoked response propagates between brain structures of a particular patient. See Casali et al. ${ }^{10}$ for details of this methodology. Note that the TMS-evoked response can also be captured by the blood oxygen-dependent percent signal change from fMRI and thus measured in the thalamus as well as cortical structures. BAER = brainstem auditory evoked response; VEP = visual evoked potentials.

covery suggests DBS is helpful for recovery in the setting of intact thalamocortical circuitry. Of the 13 who received DBS and did not recover, only 2 patients met criteria. Only $15 \%$ of patients met the electrophysiological criteria.

A novel measure that has been predictive of recovery from a VS and directly probes the structural connectivity of white matter tracts is the TMS-evoked response, which has been referred to as a measure of the causal interaction between 2 brain areas. ${ }^{50}$ Cortical connectivity as measured by the TMS-evoked response reliably changes as patients emerge from a VS to an MCS such that there is propagation of the response to more brain areas and in a more "complex" fashion (Fig. 1C). ${ }^{61}$ TMS stimulation of the brain in different cognitive states such as wakefulness, 
sleep,$^{50}$ task, ${ }^{36}$ and levels of coma results in differential complexity of the TMS-evoked response. ${ }^{10,49,61}$ It may be that the complexity of the TMS-evoked response predicts the efficacy of DBS to treat that patient's VS or MCS.

Finally, unilateral versus bilateral stimulation may affect how well DBS will activate arousal mechanisms. The literature to date does not show consistent results, and studies are confounded by the timing of DBS implantation. A meta-analysis demonstrated that of all the coma patients implanted with DBS leads who had at least 11 months to recover spontaneously, 1 of 1 unilateral and 5 of 6 bilateral stimulation patients recovered measurable degrees of consciousness. ${ }^{73}$

\section{DBS for Cognition and Memory in TBI}

Because of the widespread damage to white matter tracts and subcortical structures, including the thalamus, TBI causes profound disorders of cognition that result in disability from deficits in executive functioning. ${ }^{21}$ Few studies have tested cognitive function in the TBI patient population before and after DBS, but the cumulative data from animal and patient studies suggest that stimulation of the thalamus, frontal cortical areas, and components in the Papez circuit may be helpful for improving higher-order cognition. Recent studies from animal models and clinical data are addressing whether DBS can modulate cognitive performance in the brain-injured population.

\section{DBS Modulation of Cognitive Performance in Animal Models of TBI}

Hippocampal theta oscillations, which are thought to be related to learning and memory, particularly for spatial navigation, ${ }^{8,33}$ are decreased after TBI. ${ }^{54}$ It is hypothesized that the impaired cognition observed in TBI is related to altered oscillations, such as those seen in the hippocampus. If the desynchronization of brain oscillations mediates cognitive dysfunction, neuromodulation may be used to stimulate the injured brain to realign these oscillations and improve patient outcome. ${ }^{56}$ Prior reviews have described the use of electrical stimulation in modulating memory, ${ }^{6,38,64}$ but literature regarding the use of DBS specifically for altering cognition after TBI is more sparse.

TBI models showed a decrease in hippocampal theta oscillations in injured rats. ${ }^{19}$ Cells within the medial septal nucleus (MSN) modulate hippocampal pyramidal cells, ${ }^{2,35}$ making the MSN a target for neuromodulatory therapies to improve hippocampal function. Brief stimulation of the MSN in rats resulted in transient elevation of hippocampal theta activity and subsequent shorter escape latencies from the Barnes maze. ${ }^{42}$ Continuous $7.7-\mathrm{Hz}$ theta stimulation of the MSN also increased hippocampal theta oscillations and resulted in normalized object exploration and improved performance in the Barnes maze. ${ }^{43}$

Other targets for DBS to improve memory after TBI are the midbrain median raphe (MR) and dorsal raphe (DR) nuclei, ${ }^{9}$ which were chosen because of serotonin's potential neuroprotective and restorative effects. ${ }^{15}$ Carballosa Gonzalez et al. ${ }^{9}$ implanted electrodes into either the MR or DR nuclei and stimulated them at 8 or $24 \mathrm{~Hz}$, beginning 4-6 hours or 7 days after a fluid percussion injury.
When testing reference memory 5 weeks after injury, the authors found that $8-\mathrm{Hz}$ MR- and DR-stimulated rats implanted within 4-6 hours showed significantly shorter latencies compared with their no-stimulation counterparts. It should be noted, however, that the differences between groups had decreased or disappeared by the third day of testing, which the authors attributed to underlying spontaneous recovery. When escape latency was used to measure working memory, only the 8-Hz MR-stimulated group implanted at 4-6 hours showed shorter escape latencies compared with the no-stimulation group. ${ }^{9}$

Thalamic damage has been correlated with decreased executive function in patients with mild TBI. ${ }^{28}$ Stimulation of the central thalamus in rodents resulted in improved performance on memory tasks as well as increased activation in the dentate gyrus, a connection node of the central thalamus. ${ }^{66}$

\section{DBS Targets to Modulate Cognition in Patients}

Although only one study to date, discussed below, directly addressed changes in memory function in TBI patients, DBS data from other patient populations point to alternative targets, including the pedunculopontine nucleus ${ }^{13}$ and the fornix, ${ }^{39,47,51}$ that may modulate memory function in humans. Mixed behavioral results have been seen with stimulation of the subthalamic nucleus, anterior nucleus of the thalamus, and hippocampus. ${ }^{6}$ Noninvasive stimulation of neocortical areas such as the dorsolateral prefrontal cortex may improve aspects of executive function..$^{14,34}$

Importantly, what precludes functional independence in TBI patients is often not just the "granular" components of cognition, such as working memory and decision making, which can be objectively tested using trial-by-trial tasks, but broader abilities, such as excessive impulsive behavior and inability to regulate emotions. In the only study addressing the use of DBS to modulate cognition in TBI patients, Rezai et al. ${ }^{60}$ stimulated the bilateral nucleus accumbens and anterior limb of the internal capsule to modulate networks involved with motivation and processing of rewards. Deficits in initiating goal-directed behavior and problems of increased impulsiveness affect many of the patients with severe TBI who recover consciousness but are unable to live independently. Four TBI patients who could communicate and follow commands but were unable to live independently were included in Rezai and colleagues' study. Performance on both functional and cognitive scores improved more with concurrent rehabilitation than with stimulation alone, leading the authors to suggest that DBS seems to work better when used concurrently with behavioral therapies. Continued therapy is important, since performance on tasks testing working memory and executive planning declined once formal practicing of those skills stopped.

\section{Future Directions}

\section{Stimulation Targeting Specific Anatomical Structures}

Finite element models created to estimate the extent of activation of DBS in the brain, under different stimulation protocols, may be used to shape the area of activation to target specific anatomical structures. ${ }^{7}$ Most recently, 
Baker et al..$^{5}$ have shown that stimulation of "the wing" of the central thalamus and medial dorsal thalamic tegmental tract (which contain efferent fibers to anterior forebrain structures and en passage fibers of the internal medullary lamina that encases the central thalamic nuclei) increases the duration of arousal and vigilance in cognitively fatigued nonhuman primates. Cognitive fatigue is a common feature of TBI, limiting patients' ability to progress with rehabilitation therapies. The authors showed the best effect is derived with shaping the field of stimulation with adjacent DBS leads to match this "wing-shaped" area of the central thalamus. ${ }^{5}$

\section{DBS for Network Modulation}

Another avenue of exploration to treat decreased arousal or cognitive performance, based on the idea that DBS involves modulation of a large-scale brain network interconnected by white matter pathways, ${ }^{37}$ may be to target these white matter pathways instead of individual brainstem or thalamic nuclei. ${ }^{32}$ For example, stimulation of the corticothalamic projections or brainstem-to-thalamic projections may be more effective in increasing arousal. The zona incerta has been implicated in modulating central thalamic nuclei activation of the anterior forebrain. ${ }^{46}$ Cortical activation is decreased with $10-\mathrm{Hz}$ stimulation of the central thalamus in anesthetized rats. This effect is amplified with inhibition of neurons constituting the zona incerta, implying that the zona incerta is a modulator of cortical activation and may be a novel target to stimulate arousal in patients with decreased levels of consciousness.

Recent investigations suggest that "cortical deafferentation" may be the mechanism of impaired consciousness in refractory epilepsy. Stimulation in intralaminar nuclei of the thalamus improves behavioral arousal in the postictal state in rats with induced hippocampal seizures. ${ }^{30}$ Combined stimulation of both the pontine nucleus oralis and the central lateral nucleus of the intralaminar thalamus bilaterally results in improved behavioral arousal during a focal limbic seizure, whereas stimulation of individual nuclei did not improve behavior, in a rat model. ${ }^{40}$ These data strongly suggest that intact connectivity is required for stimulation efficacy and that dual stimulation of multiple nodes in a network can significantly boost the efficacy of DBS for global cortical function.

\section{Refining Open-Loop Stimulation}

Stimulation amplitude and frequency parameters can be tailored to the individual based on clinical response. One interesting avenue of exploration has been trying alternative patterns of stimulation. Pfaff and Banavar ${ }^{57}$ suggested that a chaotic pattern of stimulation may be more efficacious in activating the CNS than a fixed linear stimulation rate. In both normal and closed head injury mouse models with electrodes implanted in the central thalamus, stimulation delivered in a chaotic pattern led to increased arousal and locomotion compared with stimulation delivered at random intervals or fixed intervals..$^{58,69}$

\section{Alternative Stimulation Targets Within the Network}

There are numerous potential targets for modulating arousal and cognitive function, including the hippocampus, prefrontal cortex, or deeper brainstem nuclei to target global CNS neurotransmitter systems such as the dopaminergic or cholinergic systems. For example, the basal forebrain nuclei have emerged as a potential alternative target for treating decreased arousal. Activation of GABAergic neurons in the basal forebrain nuclei of mice and not the activation of cholinergic or glutaminergic neurons resulted in increased wakefulness as well as increased high gamma $(60-100 \mathrm{~Hz})$ power in frontoparietal electrodes, as measured by cortical EEG during slow-wave sleep. ${ }^{3}$ Inhibition of these neurons impaired wakefulness. Here GABAergic connections in the basal forebrain nuclei are necessary and sufficient for wakefulness in rats. ${ }^{3}$ Anterograde tracing from the basal forebrain showed connectivity to areas of the cortex, thalamus, hypothalamus, and pallidum. Gummadavelli et al. ${ }^{29}$ discussed alternative targets to modulate consciousness in the context of epilepsy, including the pedunculopontine tegmental nucleus, ventral tegmental area, lateral hypothalamus, tuberomammillary nucleus, globus pallidus internus, subthalamic nucleus, and cholinergic basal forebrain nuclei. Importantly, animals or patients with epilepsy probably have more intact underlying brain structure than patients with TBI.

\section{Conclusions and Recommendations}

TBI is an increasingly prevalent disease process that inherently affects multiple cortical and subcortical areas as well as the white matter tracts that connect these areas via processes that progress over months to years postinjury. DBS offers a means to jump-start dormant networks or modulate aberrant or desynchronized activity across brain areas to facilitate brain function. At this point, it is crucial to perform larger blinded prospective trials with TBI patients, targeting particular brain areas that have demonstrated potential for safely modulating cognition and arousal in other patient populations. Potential targets should involve one or more nodes of the "arousal network," including brainstem and centromedian or centrolateral interlaminar thalamic nuclei. It will be important to allow for time periods where DBS is off to discern the effects of DBS from the natural progression of recovery from TBI. This will require that patients be given an adequate period of at least 6-12 months to spontaneously emerge from coma. Although numerous ethical considerations must be kept in mind when treating this patient population, ${ }^{55,73}$ DBS coupled with intensive behavioral therapy may offer a means for patients who have experienced devastating brain injury to recover cognitive function and a meaningful quality of life.

\section{References}

1. Adams JH, Jennett B, McLellan DR, Murray LS, Graham DI: The neuropathology of the vegetative state after head injury. J Clin Pathol 52:804-806, 1999

2. Allen CN, Crawford IL: GABAergic agents in the medial septal nucleus affect hippocampal theta rhythm and acetylcholine utilization. Brain Res 322:261-267, 1984

3. Anaclet C, Pedersen NP, Ferrari LL, Venner A, Bass CE, Arrigoni E, et al: Basal forebrain control of wakefulness and cortical rhythms. Nat Commun 6:8744, 2015 
4. Ascherio A, Schwarzschild MA: The epidemiology of Parkinson's disease: risk factors and prevention. Lancet Neurol 15:1257-1272, 2016

5. Baker JL, Ryou JW, Wei XF, Butson CR, Schiff ND, Purpura KP: Robust modulation of arousal regulation, performance, and frontostriatal activity through central thalamic deep brain stimulation in healthy nonhuman primates. J Neurophysiol 116: 2383-2404, 2016

6. Bick SKB, Eskandar EN: Neuromodulation for restoring memory. Neurosurg Focus 40(5):E5, 2016

7. Butson CR, Cooper SE, Henderson JM, McIntyre CC: Patient-specific analysis of the volume of tissue activated during deep brain stimulation. Neuroimage 34:661-670, 2007

8. Buzsáki G: Two-stage model of memory trace formation: a role for "noisy" brain states. Neuroscience 31:551-570, 1989

9. Carballosa Gonzalez MM, Blaya MO, Alonso OF, Bramlett HM, Hentall ID: Midbrain raphe stimulation improves behavioral and anatomical recovery from fluid-percussion brain injury. J Neurotrauma 30:119-130, 2013

10. Casali AG, Gosseries O, Rosanova M, Boly M, Sarasso S, Casali KR, et al: A theoretically based index of consciousness independent of sensory processing and behavior. Sci Transl Med 5:198ra105, 2013

11. Chudy D, Deletis V, Rogic M, Paradzik V, Grahovac G: Deep brain stimulation for the early treatment of the minimal consciousness state and vegetative state. Stereotact Funct Neurosurg 90:1-10, 2017

12. Cohadon F, Richer E: Stimulation cérébrale profonde chez des patients en état végétatif post-traumatique. 25 observations. Neurochirurgie 39:281-292, 1993

13. Costa A, Carlesimo GA, Caltagirone C, Mazzone P, Pierantozzi M, Stefani A, et al: Effects of deep brain stimulation of the peduncolopontine area on working memory tasks in patients with Parkinson's disease. Parkinsonism Relat Disord 16:64-67, 2010

14. Cotelli M, Calabria M, Manenti R, Rosini S, Maioli C, Zanetti $\mathrm{O}$, et al: Brain stimulation improves associative memory in an individual with amnestic mild cognitive impairment. Neurocase 18:217-223, 2012

15. Cowen DS: Serotonin and neuronal growth factors-a convergence of signaling pathways. J Neurochem 101:11611171,2007

16. Deb S, Lyons I, Koutzoukis C, Ali I, McCarthy G: Rate of psychiatric illness 1 year after traumatic brain injury. Am J Psychiatry 156:374-378, 1999

17. Deeb W, Giordano JJ, Rossi PJ, Mogilner AY, Gunduz A, Judy JW, et al: Proceedings of the Fourth Annual Deep Brain Stimulation Think Tank: a review of emerging issues and technologies. Front Integr Neurosci 10:38, 2016

18. Faul M, Xu L, Wald MM, Coronado VG: Traumatic Brain Injury in the United States: Emergency Department Visits, Hospitalizations, and Deaths. Atlanta: Centers for Disease Control and Prevention, National Center for Injury Prevention and Control, 2010 (https://www.cdc.gov/ traumaticbraininjury/pdf/blue_book.pdf) [Accessed June 14, 2018]

19. Fedor M, Berman RF, Muizelaar JP, Lyeth BG: Hippocampal theta dysfunction after lateral fluid percussion injury. J Neurotrauma $27: 1605-1615,2010$

20. Fisher R, Salanova V, Witt T, Worth R, Henry T, Gross R, et al: Electrical stimulation of the anterior nucleus of thalamus for treatment of refractory epilepsy. Epilepsia 51:899-908, 2010

21. Frieden TR, Houry D, Baldwin G: Report to Congress on Traumatic Brain Injury in the United States: Epidemiology and Rehabilitation. Atlanta: National Center for Injury Prevention and Control, 2015

22. Giacino JT, Fins JJ, Laureys S, Schiff ND: Disorders of consciousness after acquired brain injury: the state of the science. Nat Rev Neurol 10:99-114, 2014
23. Giacino JT, Kalmar K: The vegetative and minimally conscious states: a comparison of clinical features and functional outcome. J Head Trauma Rehabil 12:36-51, 1997

24. Giacino JT, Whyte J, Bagiella E, Kalmar K, Childs N, Khademi A, et al: Placebo-controlled trial of amantadine for severe traumatic brain injury. N Engl J Med 366:819-826, 2012

25. Goldfine AM, Schiff ND: What is the role of brain mechanisms underlying arousal in recovery of motor function after structural brain injuries? Curr Opin Neurol 24:564-569, 2011

26. Gosseries O, Di H, Laureys S, Boly M: Measuring consciousness in severely damaged brains. Annu Rev Neurosci 37:457-478, 2014

27. Graham DI, Maxwell WL, Adams JH, Jennett B: Novel aspects of the neuropathology of the vegetative state after blunt head injury. Prog Brain Res 150:445-455, 2005

28. Grossman EJ, Inglese M: The role of thalamic damage in mild traumatic brain injury. J Neurotrauma 33:163-167, 2016

29. Gummadavelli A, Kundishora AJ, Willie JT, Andrews JP, Gerrard JL, Spencer DD, et al: Neurostimulation to improve level of consciousness in patients with epilepsy. Neurosurg Focus 38(6):E10, 2015

30. Gummadavelli A, Motelow JE, Smith N, Zhan Q, Schiff ND, Blumenfeld $\mathrm{H}$ : Thalamic stimulation to improve level of consciousness after seizures: evaluation of electrophysiology and behavior. Epilepsia 56:114-124, 2015

31. Hassler R, Ore GD, Bricolo A, Dieckmann G, Dolce G: EEG and clinical arousal induced by bilateral long-term stimulation of pallidal systems in traumatic vigil coma. Electroencephalogr Clin Neurophysiol 27:689-690, 1969

32. Henderson JM: "Connectomic surgery": diffusion tensor imaging (DTI) tractography as a targeting modality for surgical modulation of neural networks. Front Integr Nuerosci 6:15, 2012

33. Hernández-Pérez JJ, Gutiérrez-Guzmán BE, Olvera-Cortés ME: Hippocampal strata theta oscillations change their frequency and coupling during spatial learning. Neuroscience 337:224-241, 2016

34. Javadi AH, Walsh V: Transcranial direct current stimulation (tDCS) of the left dorsolateral prefrontal cortex modulates declarative memory. Brain Stimul 5:231-241, 2012

35. Jeantet $Y$, Jaffard R: Influence of the medial septal nucleus on the excitability of the commissural path-CA1 pyramidal cell synapse in the hippocampus of freely moving mice. Neuroscience 8:291-297, 1983

36. Johnson JS, Kundu B, Casali AG, Postle BR: Task-dependent changes in cortical excitability and effective connectivity: a combined TMS-EEG study. J Neurophysiol 107:2383-2392, 2012

37. Karas PJ, Mikell CB, Christian E, Liker MA, Sheth SA: Deep brain stimulation: a mechanistic and clinical update. Neurosurg Focus 35(5):E1, 2013

38. Kim K, Ekstrom AD, Tandon N: A network approach for modulating memory processes via direct and indirect brain stimulation: toward a causal approach for the neural basis of memory. Neurobiol Learn Mem 134 (Pt A):162-177, 2016

39. Koubeissi MZ, Kahriman E, Syed TU, Miller J, Durand DM: Low-frequency electrical stimulation of a fiber tract in temporal lobe epilepsy. Ann Neurol 74:223-231, 2013

40. Kundishora AJ, Gummadavelli A, Ma C, Liu M, McCafferty C, Schiff ND, et al: Restoring conscious arousal during focal limbic seizures with deep brain stimulation. Cereb Cortex 27:1964-1975, 2017

41. Lammi MH, Smith VH, Tate RL, Taylor CM: The minimally conscious state and recovery potential: a follow-up study 2 to 5 years after traumatic brain injury. Arch Phys Med Rehabil 86: $746-754,2005$

42. Lee DJ, Gurkoff GG, Izadi A, Berman RF, Ekstrom AD, 
Muizelaar JP, et al: Medial septal nucleus theta frequency deep brain stimulation improves spatial working memory after traumatic brain injury. J Neurotrauma 30:131-139, 2013

43. Lee DJ, Gurkoff GG, Izadi A, Seidl SE, Echeverri A, Melnik M, et al: Septohippocampal neuromodulation improves cognition after traumatic brain injury. J Neurotrauma 32:18221832,2015

44. Levin HS, Saydjari C, Eisenberg HM, Foulkes M, Marshall LF, Ruff RM, et al: Vegetative state after closed-head injury: a traumatic coma data bank report. Arch Neurol 48:580_ 585,1991

45. Li S, Zaninotto AL, Neville IS, Paiva WS, Nunn D, Fregni F: Clinical utility of brain stimulation modalities following traumatic brain injury: current evidence. Neuropsychiatr Dis Treat 11:1573-1586, 2015

46. Liu J, Lee HJ, Weitz AJ, Fang Z, Lin P, Choy M, et al: Frequency-selective control of cortical and subcortical networks by central thalamus. eLife 4:e09215, 2015

47. Lozano AM, Fosdick L, Chakravarty MM, Leoutsakos JM, Munro C, Oh E, et al: A phase II study of fornix deep brain stimulation in mild Alzheimer's disease. J Alzheimers Dis $\mathbf{5 4 : 7 7 7 - 7 8 7 , 2 0 1 6}$

48. Magrassi L, Maggioni G, Pistarini C, Di Perri C, Bastianello S, Zippo AG, et al: Results of a prospective study (CATS) on the effects of thalamic stimulation in minimally conscious and vegetative state patients. J Neurosurg 125:972-981, 2016

49. Massimini M, Boly M, Casali A, Rosanova M, Tononi G: A perturbational approach for evaluating the brain's capacity for consciousness. Prog Brain Res 177:201-214, 2009

50. Massimini M, Ferrarelli F, Huber R, Esser SK, Singh H, Tononi G: Breakdown of cortical effective connectivity during sleep. Science 309:2228-2232, 2005

51. Miller JP, Sweet JA, Bailey CM, Munyon CN, Luders HO, Fastenau PS: Visual-spatial memory may be enhanced with theta burst deep brain stimulation of the fornix: a preliminary investigation with four cases. Brain 138:1833-1842, 2015

52. Morrell MJ, Halpern C: Responsive direct brain stimulation for epilepsy. Neurosurg Clin N Am 27:111-121, 2016

53. Moruzzi G, Magoun HW: Brain stem reticular formation and activation of the EEG. Electroencephalogr Clin Neurophysiol 1:455-473, 1949

54. Paterno R, Metheny H, Xiong G, Elkind J, Cohen AS: Mild traumatic brain injury decreases broadband power in area CA1. J Neurotrauma 33:1645-1649, 2016

55. Patuzzo S, Manganotti P: Deep brain stimulation in persistent vegetative states: ethical issues governing decision making. Behav Neurol 2014:641213, 2014

56. Pevzner A, Izadi A, Lee DJ, Shahlaie K, Gurkoff GG: Making waves in the brain: what are oscillations, and why modulating them makes sense for brain injury. Front Syst Neurosci 10:30, 2016

57. Pfaff D, Banavar JR: A theoretical framework for CNS arousal. BioEssays 29:803-810, 2007

58. Quinkert AW, Pfaff DW: Temporal patterns of deep brain stimulation generated with a true random number generator and the logistic equation: effects on CNS arousal in mice. Behav Brain Res 229:349-358, 2012

59. Ragazzoni A, Cincotta M, Giovannelli F, Cruse D, Young GB, Miniussi C, et al: Clinical neurophysiology of prolonged disorders of consciousness: From diagnostic stimulation to therapeutic neuromodulation. Clin Neurophysiol 128:16291646,2017

60. Rezai AR, Sederberg PB, Bogner J, Nielson DM, Zhang J, Mysiw WJ, et al: Improved function after deep brain stimulation for chronic, severe traumatic brain injury. Neurosurgery 79:204-211, 2016
61. Rosanova M, Gosseries O, Casarotto S, Boly M, Casali AG, Bruno MA, et al: Recovery of cortical effective connectivity and recovery of consciousness in vegetative patients. Brain 135:1308-1320, 2012

62. Schiff ND, Giacino JT, Kalmar K, Victor JD, Baker K, Gerber M, et al: Behavioural improvements with thalamic stimulation after severe traumatic brain injury. Nature 448:600603, 2007 (Erratum in Nature 452:120, 2008)

63. Shah SA, Schiff ND: Central thalamic deep brain stimulation for cognitive neuromodulation - a review of proposed mechanisms and investigational studies. Eur J Neurosci 32:1135-1144, 2010

64. Sharma M, Deogaonkar M, Rezai A: Assessment of potential targets for deep brain stimulation in patients with Alzheimer's disease. J Clin Med Res 7:501-505, 2015

65. Shin SS, Dixon CE, Okonkwo DO, Richardson RM: Neurostimulation for traumatic brain injury. J Neurosurg 121:1219-1231, 2014

66. Shirvalkar P, Seth M, Schiff ND, Herrera DG: Cognitive enhancement with central thalamic electrical stimulation. Proc Natl Acad Sci U S A 103:17007-17012, 2006

67. Steriade M: Arousal: revisiting the reticular activating system. Science 272:225-226, 1996

68. Steriade M, Glenn LL: Neocortical and caudate projections of intralaminar thalamic neurons and their synaptic excitation from midbrain reticular core. J Neurophysiol 48:352371,1982

69. Tabansky I, Quinkert AW, Rahman N, Muller SZ, Lofgren J, Rudling J, et al: Temporally-patterned deep brain stimulation in a mouse model of multiple traumatic brain injury. Behav Brain Res 273:123-132, 2014

70. Tagliaferri F, Compagnone C, Korsic M, Servadei F, Kraus J: A systematic review of brain injury epidemiology in Europe. Acta Neurochir (Wien) 148:255-268, 2006

71. Thonnard M, Gosseries O, Demertzi A, Lugo Z, Vanhaudenhuyse A, Bruno MA, et al: Effect of zolpidem in chronic disorders of consciousness: a prospective open-label study. Funct Neurol 28:259-264, 2013

72. Tsubokawa T, Yamamoto T, Katayama Y, Hirayama T, Maejima S, Moriya T: Deep-brain stimulation in a persistent vegetative state: follow-up results and criteria for selection of candidates. Brain Inj 4:315-327, 1990

73. Vanhoecke J, Hariz M: Deep brain stimulation for disorders of consciousness: systematic review of cases and ethics. Brain Stimul 10:1013-1023, 2017

74. Yamamoto T, Katayama Y, Kobayashi K, Oshima H, Fukaya C, Tsubokawa T: Deep brain stimulation for the treatment of vegetative state. Eur J Neurosci 32:1145-1151, 2010

\section{Disclosures}

Dr. Butson reports a consultant relationship with Abbott and Functional Neuromodulation and direct stock ownership in Intelect Medical.

\section{Author Contributions}

Conception and design: Rolston, Kundu, Brock. Acquisition of data: Kundu, Brock. Analysis and interpretation of data: Kundu, Brock, Englot. Drafting the article: all authors. Critically revising the article: Rolston, Kundu, Englot, Butson. Reviewed submitted version of manuscript: Rolston, Kundu.

\section{Correspondence}

John D. Rolston: University of Utah, Salt Lake City, UT. neuropub@hsc.utah.edu. 